\title{
Effect of Gravity on Radiative Heat Feedback on Small-Scale Pool Fires Using the Radiative Absorption Model
}

\author{
Koei Yoshida ${ }^{1}$, Ryo Takahashi $^{1}$, Hiroyuki Torikai ${ }^{1} \&$ Akihiko Ito ${ }^{1}$ \\ ${ }^{1}$ Graduate School of Science and Technology, Hirosaki University, Hirosaki, Japan \\ Correspondence: Akihiko Ito, Department of Intelligent Machines and System Engineering; Graduate School of \\ Science and Technology, Hirosaki University, 3 Bunkyo-Cho, Hirosaki, 036-8561, Japan. Tel: 81-172-39-3679. \\ E-mail: aito@hirosaki-u.ac.jp
}

Received: February 12, 2016

doi:10.5539/mas.v10n10p150

\begin{abstract}
The flame characteristics of pool fires such as their height vary depending on gravity. To improve our understanding of the effects of gravity on flame characteristics, we experimentally investigated small-scale pool fires under conditions of normal to partial gravity; using the drop tower at Hirosaki University in Japan to obtain arbitrary partial gravity condition, which varied from $1 \mathrm{G}$ to $0.55 \mathrm{G}$. We performed the measurement of the temperature distribution with a thermocouple and that of the flame shape with a digital camera. Based on these data, we estimated radiative heat feedback using our new model "The radiative absorption model". It becomes easy to estimate radiative heat transfer using this model if flames have complicated shapes and time variability. From these analyses, we made clear that the radiative heat feedback of small-scale pool fires decreases under partial gravity environment.
\end{abstract}

Keywords: liquid pool fire, partial gravity environment, radiative heat feedback, radiative absorption model

\section{Introduction}

In recent years, the range of human activity is expanding to various gravity environments, for example, the exploration of Mars and the utilization of the International Space Station (ISS). Although establishing fire safety is important and critical in manned space missions, flame characteristics under various gravity environments are not clarified entirely. To promote development under space or partial-gravity environments, a fire safety assessment must be assessed under various gravity levels and fires should be suppressed during their initial stages to protect human life. To predict phenomena in the initial stages of fires, it is important to understand the effect of gravity on flame behavior which differs depending on the buoyancy. The difference of gravity level strongly influences combustion phenomena and fire safety. Some combustion research under varied gravity environments using drop towers, parabolic-trajectory airplanes, the Space Shuttle, and centrifuges has reported qualitative findings. However, there has been little combustion research into partial-gravity environments between micro and normal gravity.

From previous research, it is clear that the flame height of small-scale pool fires decreases as gravity levels decline. To clarify the mechanism of flame height decrease, flow field research of pool fires was performed by Yoshihara et al.. However, the mechanism is not sufficiently clear. It is known that the flame height of pool fires depends on fuel evaporation caused by the heat feedback of the flame. Then, we have focused on the temperature field as new approach.

Generally, in the case of small-scale (lab-size) pool fire, the heat feedback to the fuel surface is controlled by convective heat feedback and we can ignore radiative heat feedback. However, as pool fires are scaled-up to medium- or large-scale, we have to consider the radiative term. Furthermore, because pool fires formed on pans above a certain size show a pulsation phenomenon called puffing (or flickering) induced by buoyancy, the flame shapes become complicated. Then, the direct measurement of radiative heat feedback is difficult, so we have to estimate it based on the flame shape of pool fires.

There are some models to estimate radiative heat transfer from fires, for example, the model suggested by Modak, and the view factor models. Modak's model can be applied to only flames which can be expressed with polynomial expressions. But the flame observed in realistic fire transitions to turbulent and shows non-linear 
shape. On the other hand, the view factor model is originally applied to the radiative heat transfer between solid surfaces, so it assumes flame as solid or solid surface. Of course, flame is not solid, and it does not shows simple shapes like cylinder or circular cone. Then, it is hard to use these existing models to estimate the radiative heat feedback to the fuel surface of pool fires.

\subsection{Previous Study by Modak}

There is a previous approach to radiative flame modelling by Modak (1977) who described the radiative heat flux from the flame to a surface element on combustibles using an empirical time-averaged flame shape, an effective radiation temperature, and a mean gray body absorption emission coefficient. This analysis computes (1) Radiative energy fluxes to surfaces located external to the fire in any arbitrary orientation, (2) Variations of radiative heat flux along the fuel surface, from fire center to fire edge, (3) The total radiative heat transfer from the flames to the fuel surface, (4) Forward radiative heat transfer from the fire to the fuel external to the fuel surface, (5) The angular distribution of the radiative flux emitted by pool fire, and (6) The total radiative power outputted from fire. The Modak's model regards flame as mean gray body gas. The Modak's model is expressed as following equation.

$$
q_{r}=\operatorname{a\varepsilon \sigma }\left(T_{f}^{4}-T_{s}^{4}\right)
$$

Where $a[-]$ is the absorption ratio of the heat receiving surface $\sigma$ is Stefan-Boltzmann coefficient (= $\left.5.67 \times 10^{-8} \mathrm{~W} / \mathrm{m}^{2} \mathrm{~K}^{4}\right), T_{f}[\mathrm{~K}]$ is flame temperature, $T_{s}[\mathrm{~K}]$ is the temperature of heat receiving surface, and $\varepsilon$ $[-]$ is emissivity. Emissivity $\varepsilon$ when radiated from isothermal gas is expressed as:

$$
\varepsilon=1-\exp (-\alpha l)
$$

Where $\alpha[1 / \mathrm{m}]$ is the absorption coefficient which is a physical property of the fuel and depends on the amount of contained carbon. $l[\mathrm{~m}]$ is the optical thickness or the mean beam path length of flame viewed from the heat receiving surface $d A$ shown in Figure 1. Then, the emissivity $\varepsilon$ is a function of the optical thickness $l$. However, the calculation of this optical thickness $l$ is difficult because it includes a double integral. So, it is unrealistic to apply this model to realistic and complicated flame shapes.

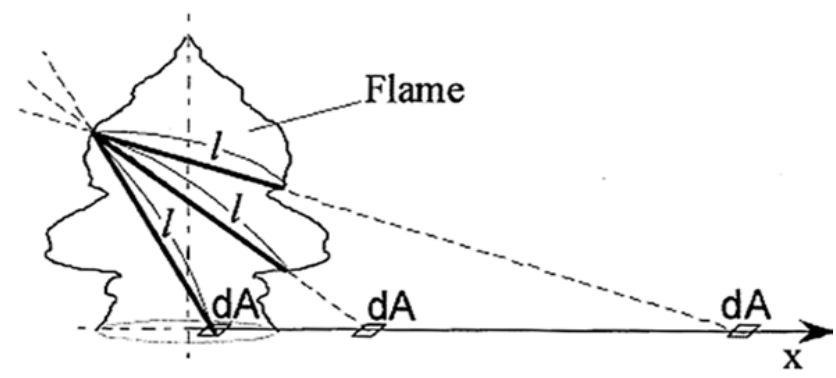

Figure 1. Schematic diagram of the optical thickness

\subsection{Purpose of This Study}

In this research, we suggest new radiative heat predicting model based on the Modak's model. The Modak's model is predicting radiative heat for an axisymmetric, horizontal, pool fire of specified flame shape, effective flame radiation temperature and a gray flame absorption coefficient as explained in the previous section. This model bases on physical dynamics and its tendency is near the experimental result. However, the Modak's model is too difficult to compute the results especially in realistic flame shapes. Then, we suggest here the new computing method that is simple and practical for the predicting radiative heat flux of the realistic fires. We call this new model "The radiative absorption model". The realistic flame shapes of small-scale pool fires were obtained from some experiments under normal and partial gravity environment. And then the estimated results of the heat feedback of pool fires using the radiation absorption model were compared with these realistic name shapes. Furthermore, based on these results, we discuss the effect of gravity on the radiative heat feedback of pool fires.

\section{The Radiative Absorption Model}

The shapes of flames, especially of flames in the immediate vicinity of the burning surface, is an important parameter controlling the radiative heat transfer to the fuel or other combustible surfaces. So, the Modak's analysis avoided arbitrary assumptions regarding shapes. Instead, characterizes flame shapes were assumed by 
means of axisymmetric flame contours obtained from actual flame photographs. Our new calculation method called "The radiative absorption model" can be applied to flames which have incompletely axisymmetric shapes. We will explain the calculative method below.

\subsection{Calculation Method}

In the radiation absorption model, flames are assumed to be isothermal and homogeneous mixtures of soot particles and other gaseous products of combustion in thermodynamic equilibrium, same as the Modak's model shown in Figure 2. And then the emissivity of flame depends on the mean beam pass length $L[\mathrm{~m}]$.

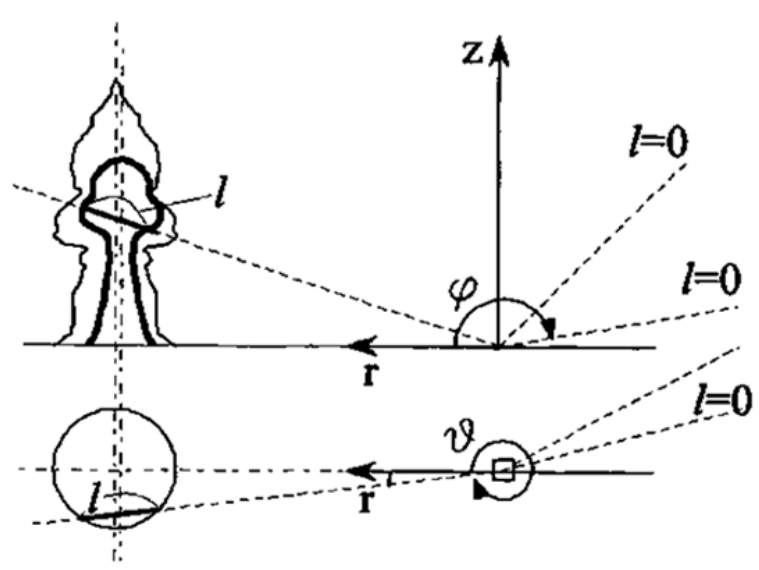

Figure 2. Schematic diagram of the Modak's model

This calculative method is different from the Modak's method in the way near a tomographic method. The calculation becomes much easier than Modak's method. The flame shape is divided in the direction of $z$-axis at stated intervals as shown in Figure 3. The coordinates of flame shape at each height are clear. In the Figure 4, $L_{i}$ is the length of the base of the ray from a receiving element for $h_{i}$. $L_{1 i}$ is the length of the base between a receiving element and name inlet at hi. $L_{2 i}$ is the length of the base between a receiving element and name outlet at $h_{i}$. These lengths are expressed as follows.

$$
\begin{gathered}
L_{i}=h_{i} / \tan \varphi \\
L_{1 i}=\left(r-x_{i o}\right) \cos \theta-\sqrt{R_{i O}^{2}-\left(r-x_{i O}\right)^{2} \sin ^{2} \theta} \\
L_{2 i}=\left(r-x_{i o}\right) \cos \theta+\sqrt{R_{i O}^{2}-\left(r-x_{i O}\right)^{2} \sin ^{2} \theta} \\
x_{i O}=\left(x_{1 i}-x_{2 i}\right) / 2, \quad R_{i O}=\left|\left(x_{1 i}-x_{2 i}\right) / 2\right|
\end{gathered}
$$

When $L_{1 i} \leq L_{i} \leq L_{2 i}$, the ray from the receiving element is inner flame at $h_{i}$ with the look up angle. The height that $L_{i}<L_{1 i}<L_{2 i}$ becomes to $L_{1 i}<L_{i}<L_{2 i}$ is defined as $h_{i n}$. The height that $L_{1 i}<L_{i}<L_{2 i}$ becomes to $L_{i}>L_{2 i}>L_{1 i}$ is defined as $h_{\text {out }}$. In the radiative absorption model, the mean beam pass length $l$ is expressed as the follow.

$$
l=\left(h_{\text {out }}-h_{\text {in }}\right) / \sin \varphi
$$

Substituting this $l$ for Equation 2, the emissivity of minutely part of flame will be obtained. Then $l$ is numerical integrated with $0<\theta<2 \pi$ and $0<\varphi<\pi / 2$ and the whole flame emissivity $\varepsilon$ will be obtained. This calculative method includes some error of the $l$ from the exactly mean beam pass length of flame. We think that the error is become small by making small the intervals in the direction of $z$. 


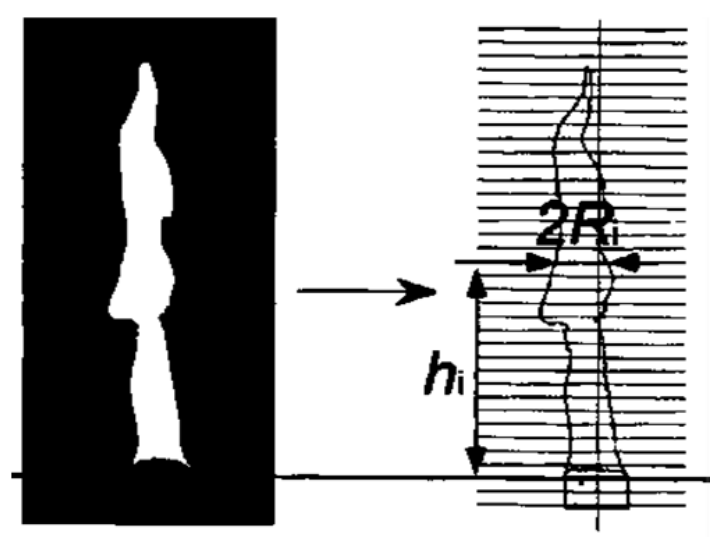

(a)

(b)

Figure 3. A flame photograph (a) and the outline of this flame shape (b)

Note. The outline is divided in the direction of $z$ at stated intervals.

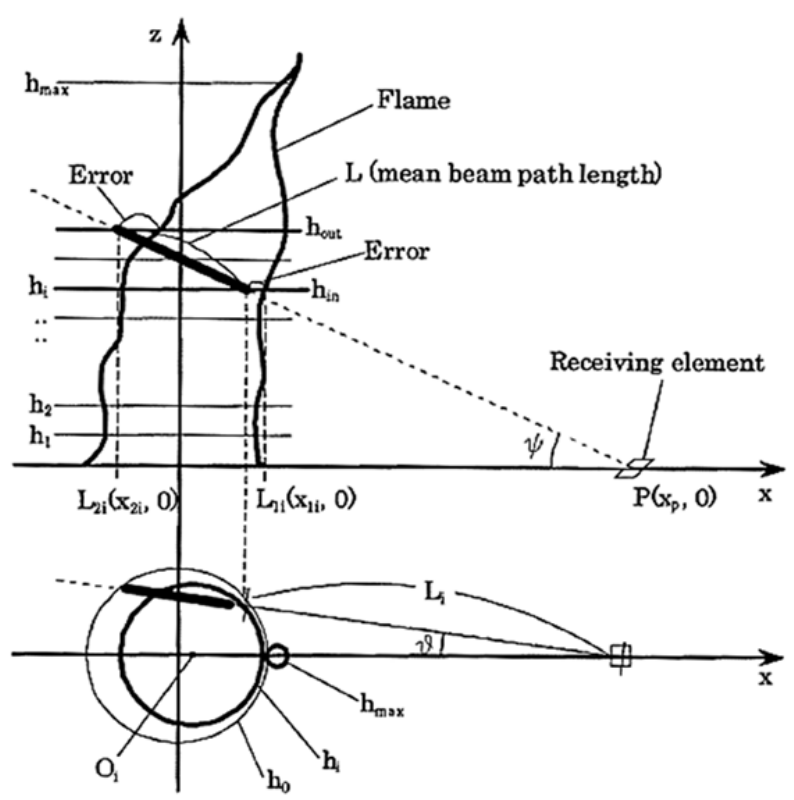

Figure 4. Schematic diagram of calculative method

Note. The flame shape is incomplete axial symmetry.

\section{2 Flame Shape Obtaining}

In the radiation absorption model, realistic flame shapes are used to estimate radiative heat correctly and to be applicable to time change explained above. However, when the name shape is recorded with the photograph from one side, the length between the points of outline crossing to the height line is assumed to be the flame diameter at each height shown in Figure 4. And the middle of these crossing points is assumed to be the center point of the circle at each height. These processes are unnecessary if a three dimensional flame shapes are obtained.

\section{Experimental Method}

\subsection{Experimental Facility and Procedure}

Arbitrary partial gravity experiments were performed using the drop tower facility at Hirosaki University. The drop tower obtains a partial-gravity environment for about one second by allowing a test package to fall about 8 $\mathrm{m}$. The gravity level declined within the range of $G=1$ to 0.55 controlling the weight of the package. The gravity level $G[-]$, is defined as $g_{a} / g$. Where $g_{a}\left[\mathrm{~m} / \mathrm{s}^{2}\right]$ is the gravitational acceleration under artificial gravity, 
and $g\left[\mathrm{~m} / \mathrm{s}^{2}\right]$ is that under normal gravity. Gravity acceleration was measured with an accelerometer (Kyowa, VAQ-700A).

Figure 5a shows a schematic of the experimental apparatus inside the test package, including the measuring system. The fuel pan is made of brass and its diameter $D[\mathrm{~mm}]$ is 15 and $26 \mathrm{~mm}$. To investigate the differences of flame characteristics between non-luminous flame and luminous, two kinds of fuel, namely Ethanol and Acetone were used as test fuels. To suppress fuel boiling, the fuel pan was set inside a cooling bath filled with temperature-modulated water. The fuel level was kept at the upper rim of the pan using a level controller. A digital camera (CASIO, EX-F1, $300 \mathrm{fps}$ ) recorded the flame behavior of the pool fires. An LED light source was attached to reveal the timing when the test package fell. All experiments were performed 1 min after ignition, because preliminary tests under normal gravity showed that the pool fire became stable within about 1 min after ignition.

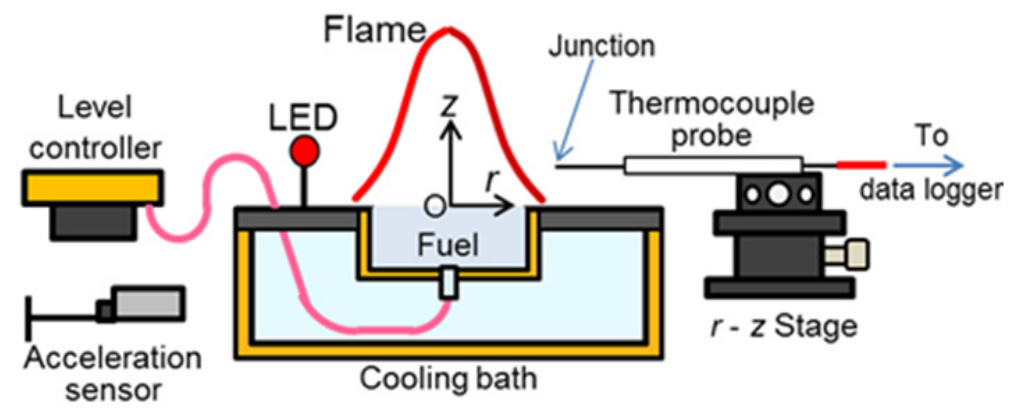

(a)Experimental apparatus

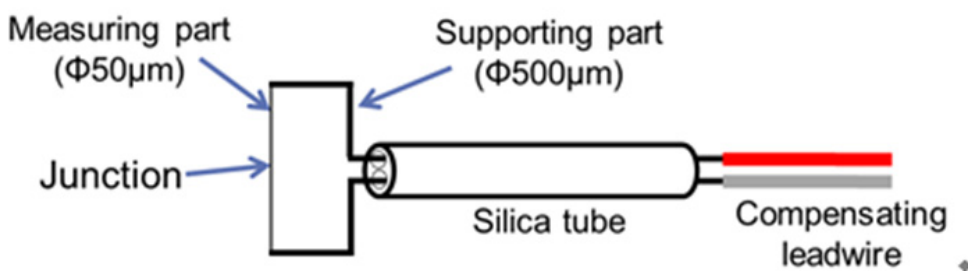

(b)Thermocouple probe

Figure 5. Experimental setup

\subsection{Temperature Measurement}

An R-type thermocouple (TANAKA, Pt-PtRh13\%) probe shown in Figure 5b was used for temperature measurement. This probe has a measuring wire of $\varphi 50 \mu \mathrm{m}$ supported by a $\varphi 500 \mu \mathrm{m}$ wire. The supporting wire is covered with a silica tube and connected to the compensating lead wire. Measured temperature was recorded by a data logger (KEYENCE, NR-1000) at intervals of $100 \mathrm{~ms}$. The thermocouple position was defined by $r$ [mm] and $z[\mathrm{~mm}]$ as shown in Figure 5a, where $r$ is the measuring point of the radial direction, and $z$ is that of the vertical direction. The origins of $r$ and $z$ are both the center of the fuel surface. We varied $r$ by $0 \sim 8 \mathrm{~mm}$, and $z$ by $1 \sim 2.5 \mathrm{~mm}$. We didn't correct the error by conductive and radiative heat loss, because the thermocouple wire hardly glows near the fuel surface where we measured in this research. In parallel, a digital camera (CASIO, EX-F1, $30 \mathrm{fps}$ ) recorded the flame behavior of the pool fires to decide measuring points.

\section{Results and Discussion}

\subsection{Temperature Distribution around Pool Fires}

Figure 6 shows the distribution of the temperature around pool fires $T[\mathrm{~K}]$ in the direction of $r$. (a) is the distribution of the ethanol pool fire at $z=2.3 \mathrm{~mm}$, and (b) is that of the acetone pool fire at $z=2.1 \mathrm{~mm}$. Near the center $(r=0)$ of the pool fires, the temperature is low (about $900 \mathrm{~K}$ ). Then, the temperature increases as the measured point comes closer to the flame sheet. While the temperature difference between $G=1$ and $G=0.55$ around the centers of the pool fires is small, the difference increases as $r$ becomes larger. 


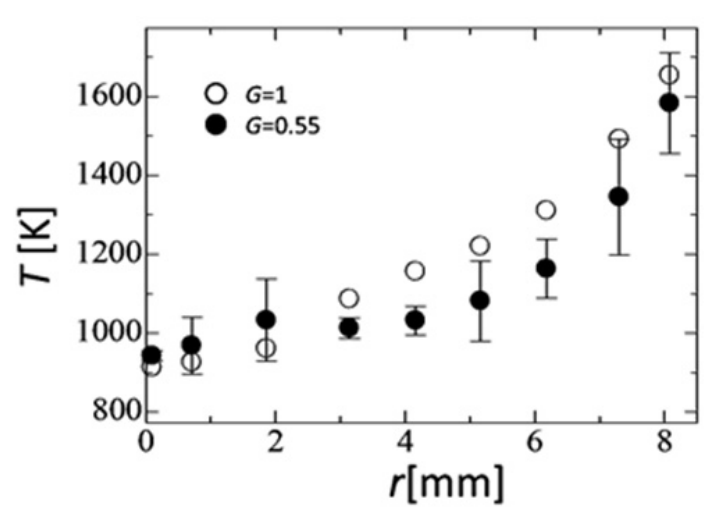

(a) Ethanol $(z=2.3 \mathrm{~mm})$

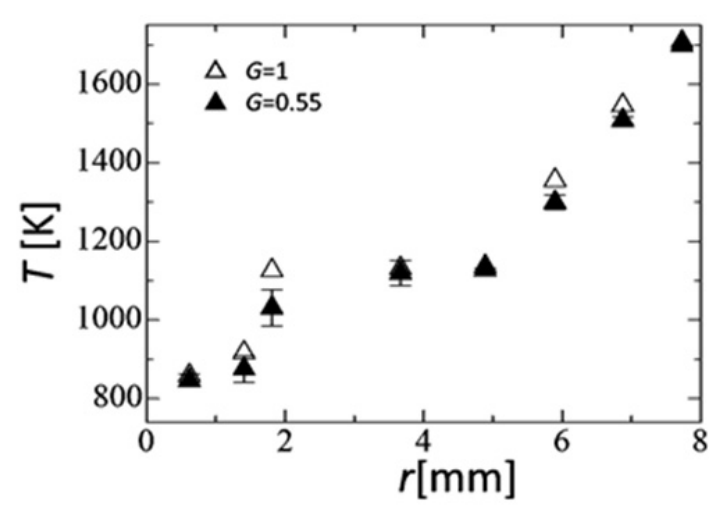

(b) Acetone $(z=2.1 \mathrm{~mm})$

Figure 6. Temperature distribution in the direction of $r$

In this research, the candidates are pool fires which has circular combustion surface, so we assumed that the temperature distributions were axially symmetrical. From the temperature distribution shown in Figure 6, we calculated average temperature of the high temperature gray gas inside the flame. These average temperatures will be used to estimate the radiative heat feedback in Section 4.2 and 4.3. The average temperatures of the ethanol pool fire at $G=1$ was $1190.8 \mathrm{~K}$, and that at $G=0.55$ was $1128.8 \mathrm{~K}$. The ratio of the decrease in temperature at $G=0.55$ compared with $G=1$ is $5.2 \%$. On the other hand, the average temperature of the acetone pool fire at $G=1$ was $1222.2 \mathrm{~K}$ and that at $G=0.55$ was $1188.3 \mathrm{~K}$. The ratio of the decrease in temperature at $G=0.55$ compared with $G=1$ is $2.8 \%$. In the case of both fuels, the average temperature decreases under a partial gravity environment.

\subsection{Radiative Heat Feedback of Steady Pool Fires}

Shown in Equation 1, the heat flux of the radiative heat feedback in pool fires $q_{r}$ [W/ $\left./ \mathrm{cm}^{2}\right]$ is given by $q_{r}=a \sigma \varepsilon\left(T_{f}^{4}-T_{s}^{4}\right)$. The absorption ratio of the heat receiving surface $a$ is assumed as 1 . The average temperature inside the flame at $z=2.3 \mathrm{~mm}$ (ethanol, $G=1: 1190.8 \mathrm{~K}$; ethanol, $G=0.55: 1128.8 \mathrm{~K}$; acetone, $G=$ 1: $1222.2 \mathrm{~K}$; acetone, $G=0.55: 1188.3 \mathrm{~K}$ ) is used as $T_{f}$. In this research, we assumed a micro region of the fuel surface center as the heat receiving surface $d A$. So, the boiling point of liquid fuels (ethanol: $351.5 \mathrm{~K}$, acetone: $329.7 \mathrm{~K}$ ) was used as $T_{s}$.

Based on the radiative absorption model, emissivity is given by $\varepsilon=1-\exp (-\alpha l)$.The absorption coefficient $\alpha$ is a physical property of the fuel and depends on the amount of contained carbon. Because the absorption coefficients $\alpha$ of test fuels (ethanol and acetone) were not clear, we estimated them based on the contained carbon amount (ethanol: 0.5 , acetone: 0.75 ). Therefore, emissivity $\varepsilon$ changes as $l$ varies. $l$ was obtained from the flame photos as shown in Figure 7a, and was assumed as the straight distance from the heat receiving surface to the flame sheet. As shown in Figure $7 \mathrm{~b}$, the receiving surface $d A$ is the micro region of the fuel surface center O. Also, angles $\varphi[\mathrm{rad}]$ and $\theta[\mathrm{rad}]$ are defined as shown in Figure $7 \mathrm{~b}$.

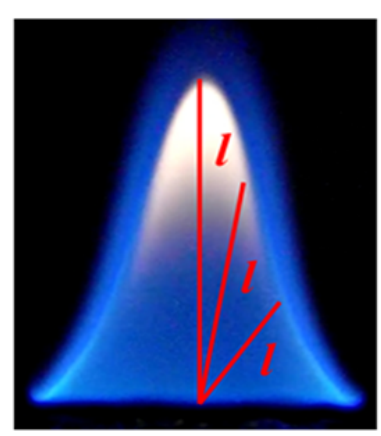

(a) Flame photograph and optical thickness

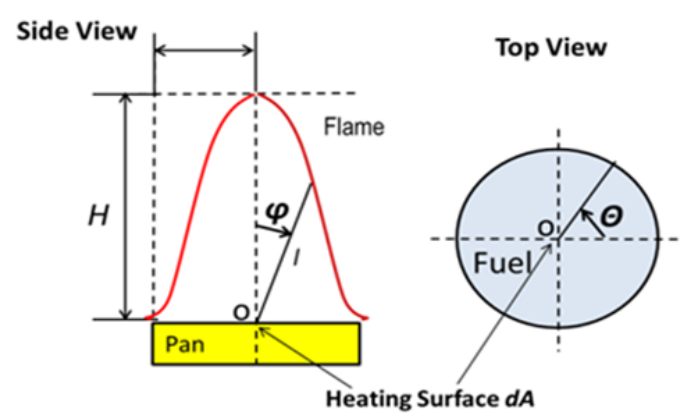

(b) Schematic of optical thickness obtaining

Figure 7. Radiative absorption model 
In this research, flames are assumed to be axially symmetrical. Then, $q_{r}$ and $\varepsilon$ vary over the range of $0<\varphi<\pi / 2$. Figure 8 shows the distribution of $q_{r}$ in the ethanol pool fire under normal and partial gravity environments. When $\varphi=0, q_{r}$ decreases significantly in $G=0.55$, because the flame height decrease directly influences the decline of $l$. On the other hand, at $\varphi=1$, the difference of $q_{r}$ between $G=1$ and 0.55 is small, because $l$ is about the same in both $G=1$ and 0.55 . The radiative heat flux from the whole flame $q_{r \text {,all }}$ [W] was found by double integration of $q_{r}$ for $0<\varphi<\pi / 2$ and $0<\theta<2 \pi$ in a circumferential direction as given by the following equation.

$$
q_{r, \text { all }}=\int_{0}^{\frac{\pi}{2}} \int_{0}^{2 \pi} q_{r} \cdot d \theta \cdot d \varphi
$$

Then, we obtained the radiative heat feedback amount $Q_{r}$ [W] by multiplying $q_{r, \text { all }}$ by the area of fuel surface $\left(1.76 \times 10^{-4} \mathrm{~m}^{2}\right)$. When the test fuel is ethanol, $Q_{r}$ is $0.35 \mathrm{~W}(G=1)$, and $0.29 \mathrm{~W}(G=0.55)$, respectively. On the other hand, when the test fuel is acetone, $Q_{r}$ is $0.72 \mathrm{~W}$ at $G=1$, and $0.67 \mathrm{~W}$ at $G=0.55$, respectively. From these results, it is found that the radiative terms of heat feedback in pool fires decrease under partial gravity environments. The decreasing ratios of $Q_{r}$ under a partial gravity environment are $17.1 \%$ (ethanol), and $6.9 \%$ (acetone). However, the absolute decrease in $Q_{r}$ is small, so it can be said that the effect of gravity on the radiative heat feedback is small.

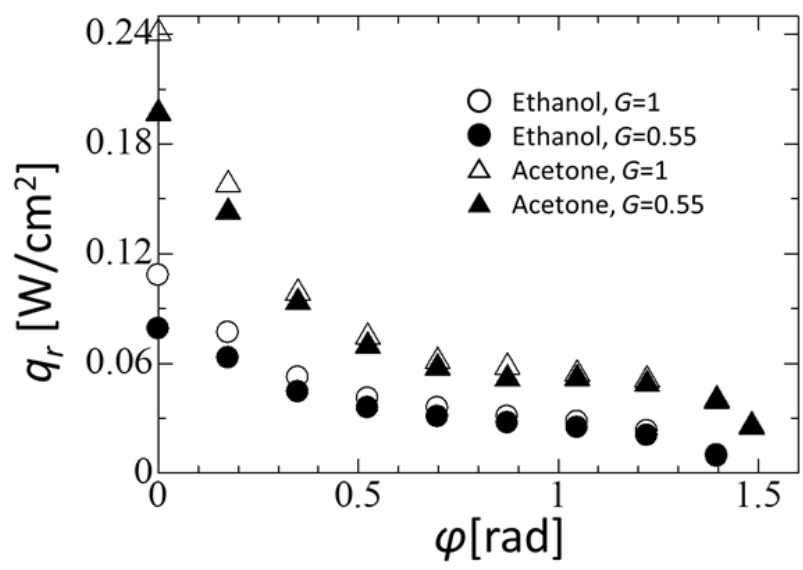

Figure 8. Radiative heat flux distribution

\subsection{Radiative Heat Feedback of Unsteady (Puffing) Pool Fires}

Using the same method in Section 4.2, we estimated the radiative heat feedback of unsteady (puffing) pool fires. Because in the case of puffing fire, flame shapes have time variability and complication, it is not appropriate to obtain flame shapes from only one flame photo. Then, we obtained flame shapes from continuous images of puffing fire for one cycle pulsation recorded by a high-speed camera (300 fps) shown in Figure 9 . The estimation was done for acetone pool fire which pan diameter $D$ is $26 \mathrm{~mm}$, and parameters except for the optical thickness $l$ are same as steady pool fires in Section 4.2. Because the temperature measurement of puffing pool fires with a thermocouple is difficult, we used the same temperature $T_{f}$ as steady acetone pool fire which $D=15 \mathrm{~mm}$. In this research, we discuss pool fires which have circular combustible surface. So, flames were assumed as axial symmetry alike in Section 4.2. 


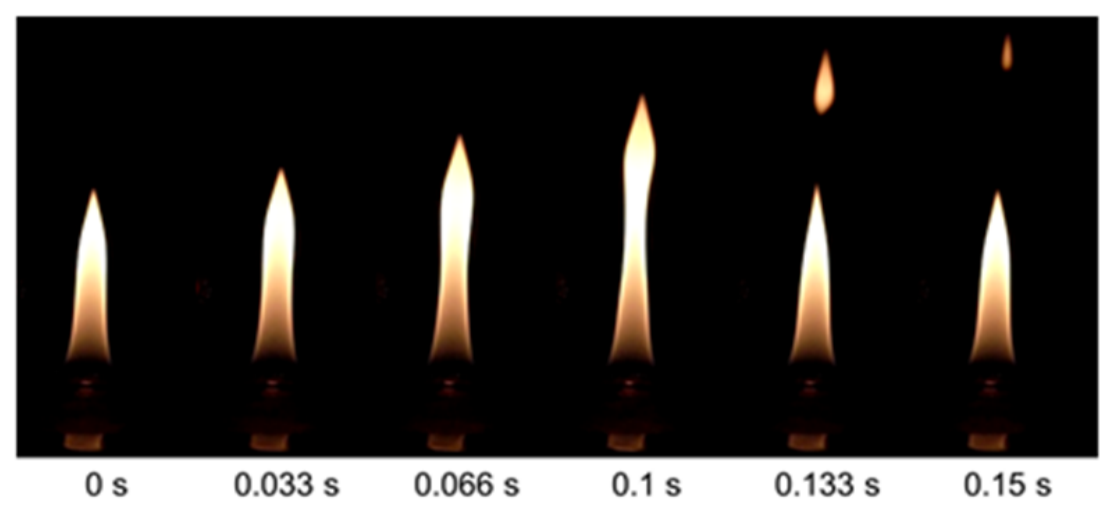

(a)Normal gravity environment $(G=1)$

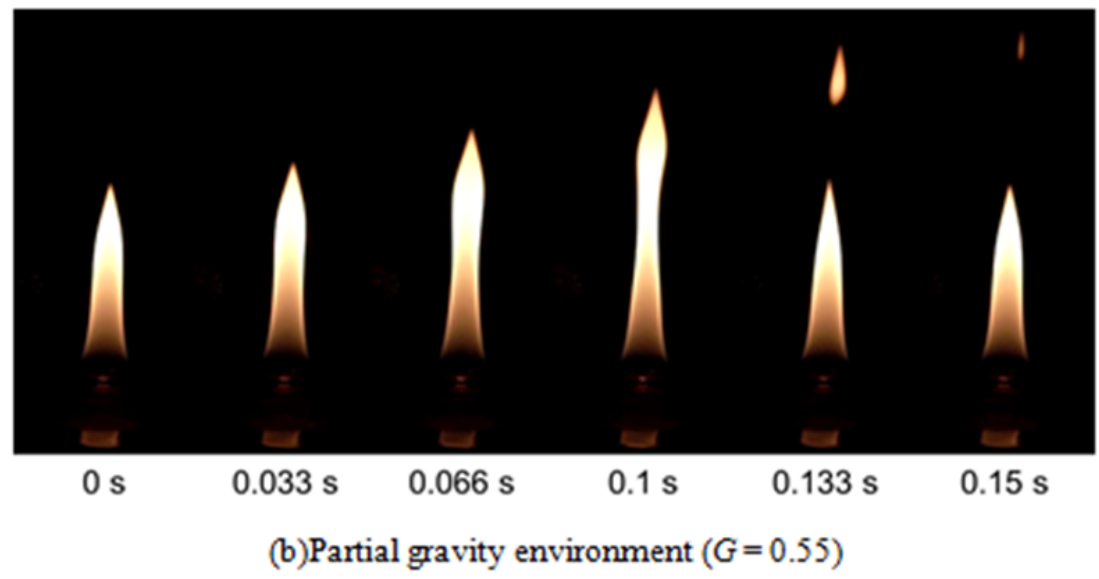

Figure 9. Continuous photographs of acetone pool fire $(D=26 \mathrm{~mm})$

Figure 10a shows a flame photograph of acetone pool fire $(G=1)$ and its optical thickness $l$. Figure $10 \mathrm{~b}$ shows the distribution of $q_{r}$ corresponding to this photograph. At $\varphi=0, l$ and $q_{r}$ are large. On the other hand, at constricted part of the flame, the optical thickness $l$ and the radiative heat flux $q_{r}$ are small. Like these, we can estimate the radiative heat flux of pool fires with complicated flame shapes using the radiation absorption model.

Figure 11 shows the time history of the radiative heat feedback amount $Q_{r}$. At $0.1 \mathrm{~s}(G=1)$ or $0.13 \mathrm{~s}(G=0.55)$, the flame extends and $Q_{r}$ becomes larger than the starting of pulsation. After that, the flame becomes small nearly identical to the first shape, and also $Q_{r}$ comes close to the original value. On the other hand, the absolute value of $Q_{r}$ under partial gravity environment is smaller than that under normal gravity. The maximum value of $Q_{r}$ under normal gravity is $0.432 \mathrm{~W}$, and that under partial gravity is $0.339 \mathrm{~W}$. Comparing these maximum value, the ratio of decrease is $21 \%$.

As mentioned above, we can easily estimate the radiative heat feedback of pool fires if they have complicated and time variability using "the radiative absorption model". Furthermore, this model is applicable to pool fires under various gravity environments. In the study for pool flames of realistic fires, the assessment of radiation is important. So, we think that this model is useful to study the combustion phenomena under various gravity environments to establish fire safety. 


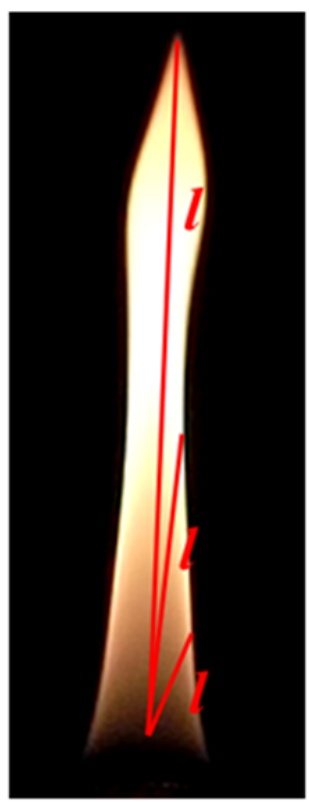

(a) Flame photograph and optical thickness

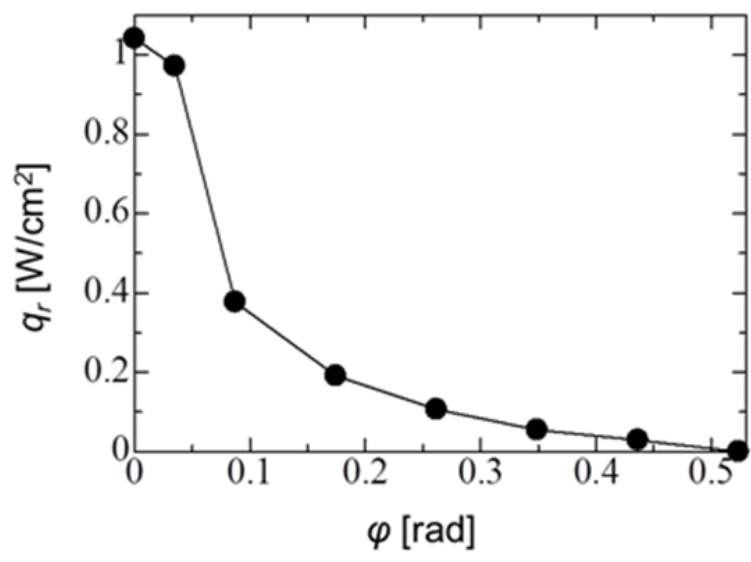

(b) The distribution of $q_{x}$ in the direction of $\varphi$

Figure 10. An example for heat feedback estimation of puffing pool fire (acetone, $G=1$ )

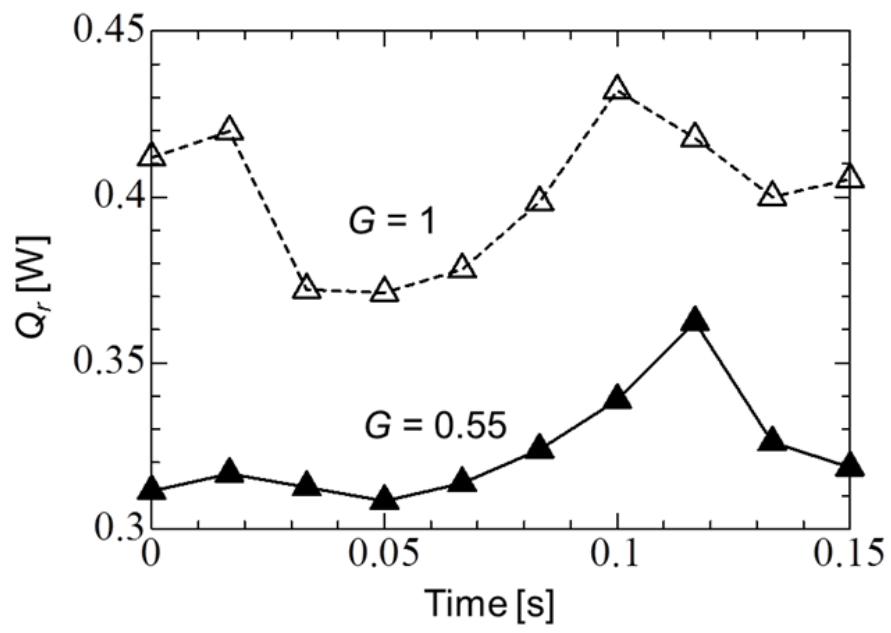

Figure 11. The time history of $Q_{r}$

\section{Conclusion}

In this study, we experimentally investigated the temperature field and the flame shapes of small-scale pool fires under partial gravity environment $(G=0.55 \sim 1)$, and estimated the radiative heat feedback amount. The following conclusions were summarized here.

(1) The average temperature of the high temperature gas inside pool fires decreased under partial gravity environments. The decreasing ratio is $5.2 \%$ (ethanol) and $2.8 \%$ (acetone).

(2) The radiative feedback amount was estimated from the temperature distribution using "the radiative absorption model". Under partial gravity environment, the radiation decreased by $17.1 \%$ (ethanol) and $6.9 \%$ acetone) when pool fires are steady (pan diameter $D=15 \mathrm{~mm}$ ). But the absolute amount of radiation is small, so effect of gravity on radiation of small-scale pool fires is little.

(3) Using the radiation absorption model, we could estimate the radiative heat feedback of unsteady (puffing) pool fires (acetone, $D=26 \mathrm{~mm}$ ). Under partial gravity environment, the maximum radiative heat feedback amount decreased by $21 \%$. 


\section{Acknowledgments}

We would like to thank Mayumi Fukuda working in HATSUTA SEISAKUSHO Co., Ltd for development of the radiative absorption model and discussions.

\section{References}

Abe, H., Ito, A., \& Torikai, H. (2015). Effect of gravity on puffing phenomena of liquid pool fires. Proceedings of Combustion Institute 35 (pp. 2581-2587). http://dx.doi.org/10.1016/j.proci.2014.05.080

Bryant, D., \& Judd, M. D. (1995). Proceedings of the 10th Anniversary of First ESA Parabolic Flight Campaign Workshop. ESA, 99-101.

Drysdale, D. (2011). An Introduction to Fire Dynamics (3rd Ed.). John Wiley \& Sons.

Friedman, R., \& Urdan, D. L. (1993). Contributions of microgravity test results to the design of spacecraft fire-safety systems. AIAA Paper, 93-1152.

Fukuda, M. (2008). Development of Flame Radiative Absorption Model Applicable to Realistic Fires. PhD Thesis, Graduate School of Science and Technology, Hirosaki University. In: Japanese.

Fukuda, M., Kudo, Y., Torikai, H., \& Ito, A. (2007). Flame Radiation Absorption Model Applicable to Realistic Fires. Proceedings of JAFSE Annual Symposium, 56-57. In: Japanese. http://dx.doi.org/10.1016/j.proci.2012.06.088

Kashiwagi, T., Mcgrattan, K. B., Olson, S. L., Fujita, O., Kikuchi, M., \& Ito, K. (1996). Effects of slow wind on localied radiative ignition and transition to flame spread in microgravity. Proceedings of Combustion Institute, 26, 1345-1352. http://dx.doi.org/10.1016/S0082-0784 (96) 80352-3

Modak, A. T. (1977). Thermal radiation from pool fires. Combustion and Flame, 29, $177-185$. http://dx.doi.org/10.1016/0010-2180 (77) 90106-7

Orson, S. L. (1987). The effect of microgravity on flame spread over a thin fuel, NASA TM-100195.

Ramachandra, P. A., Altenkirch, R. A., Bhattachajee, S., Tang, L., Sacksteader, K., \& Wolverton, M. K. (1995). The behavior of flames spreading over thin solids in microgravity. Combustion and Flame, 100, 71-84. http://dx.doi.org/10.1016/0010-2180 (94) 00046-U

Rasbash, D. J., Rogowski, Z. E., \& Stark, G. W. (1956). Properties of Fires of Liquids. Fuel, 35, 94-107.

Sanchez, Tafira, C., Linan, A., Salva, J. A., Conchero, G., Juste, G. L., \& Esteban, F. (1989). Combustion Experiments during KC-135 Parabolic Flights. ESA SP-1113, 53-64.

Sato, H., Amagai, K., \& Arai, M. (2008). Scale Modeling of Puffing Frequencies in Pool Fires Related with Froude Number. Progress in Scale Modeling, Springer, 133-147

Shipp, M., \& Spearpoint, M. (1994). The Detection of Fires in Micro-gravity. Fire Safety Science Proceedings of the 4th International Symposium, 739-750. http://dx.doi.org/10.3801/IAFSS.FSS.4-739

West, J., Tang, L., Altenkirch, R. A., Bhattachajee, S., Sacksteader, K., \& Delichatsios, M. A. (1996). Quiescent flame spread over thick fuels in microgravity. Proceedings of Combustion Institute, 26, 1335-1343. http://dx.doi.org/10.1016/S0082-0784 (96) 80352-3

Yoshihara, N., Ito, A., \& Torikai, H. (2013). Flame characteristics of small-scale pool fires under low gravity environments. Proceedings of Combustion Institute, 34, 2599-2606. http://dx.doi.org/10.1016/j.proci.2012.06.088

\section{Copyrights}

Copyright for this article is retained by the author(s), with first publication rights granted to the journal.

This is an open-access article distributed under the terms and conditions of the Creative Commons Attribution license (http://creativecommons.org/licenses/by/3.0/). 